\title{
Evaluation of a public expense-covered gynecologic screening program in Japan 2005-2009
}

\author{
Hiroshi Takagi, Satoshi Ichigo, Kazutoshi Matsunami, Atsushi Imai* \\ Department of Obstetrics and Gynecology, Matsunami General Hospital, Kasamatsu, Gifu, Japan. \\ Email: ${ }^{*}$ aimai@matsunami-hsp.or.jp
}

Received 14 April 2011; revised 31 May 2011; accepted 8 June 2011.

\begin{abstract}
Introduction: In Japan, there is free physical checkup programs of cancer screening, by which asymptomatic participants undergo a medical examination at public expense. The present study aims to describe their gynecologic findings and compare them with the literatures reported from general hospitals and selfpaid check-up programs. Methods: Medical records of Japanese women, who underwent gynecological examinations at public expense between 2005 and 2009, were retrospectively reviewed. Results: Of the cervical smears from 2850 women aged 21 - 82 years, $33(1.1 \%)$ were classified as dysplastic and malignant changes: 28 of low-grade squamous intraepithelial lesion (LSIL), 3 high-grade squamous intraepithelial lesion (HSIL), 2 atypical squamous cells of undeterimined significance (ASC-US). No case of cervical squamous cell carcinoma or adenocarcinoma was found. Ultrasonographic examination detected uterus enlargements and ovary tumors in less than $1 \%$ of cases. Most of participants $(\mathbf{9 8 \%} \%)$ revealed no gynecologic abnormalities. Conclusion: Annual gynecologic screening and proper follow-up programs even against asymptomatic women may remarkably reduce the probability of (pre)malignant disease.
\end{abstract}

Keywords: Cervical Smear Screening; Transvaginal Sonography; Gynecologic Check-up; Oncology

\section{INTRODUCTION}

Cervical intraepithelial neoplasia typically develops into invasive cancer over a 10-year period and apparent cases of rapidly progressive cervical cancer are likely to be among women who have escaped screening and proper follow-up [1-6]. The cervical smear (Papanicolaou, Pap smear) is a routine screening test used for the detection of early cervical abnormalities, namely precancerous dysplastic changes of the uterine cervix [1-6]. Organized screening programs for cervical cancer using the cervical smears have been shown to be effective in decreasing mortality and incidence from the disease [1,7]. The cervical screening is a relatively simple, low cost and noninvasive method. Together with transvaginal ultrasonography for detection of ovarian and uterine tumors, a routine cervical screening reduces the probability of developing gynecological malignant diseases.

In many countries, undergoing cancer screening is not mandatory but voluntary. The level of knowledge and attitude toward screening are related to multiple factors such as ethnicity, place of residence, income, and socialeconomic status [8-12]. In Japan, there are free physical check-up programs of cancer screening, by which asymptomatic participants undergo a medical examination at public expense. The present study aims to describe their gynecologic findings and compare them with the literatures reported from general hospitals and self-paid check-up programs.

\section{METHODS}

Between January 2005 and December 2009, 2850 asymptomatic women, age 21-82, visited one of four Kasamatsu City-agreed gynecologic physicians for their physical check-up. The cost was fully covered by the municipal corporation. Gynecologic examinations included routine cancer screening (Papanocolaou test), transvaginal ultrasonography, and pelvic examination by a gynecologist. Cervical and endometrial smears were taken using a speculum and brush and classified into 6 categories: normal, low-grade squamous intraepithelial lesions (LSIL), high-grade squamous intraepithelial lesions (HSIL), atypical squamouse cells of undetermined significance (ASC-US), cervical carcinoma, cervical adenocarcinoma. When classified as inadequate, the participants were soon resubmitted to smear examination. Their records of gynecologic findings were retrospectively reviewed.

\section{RESULTS}

Table 1 shows the cytologic and ultrasonografic findings 
Table 1. Gynecologic findings of participants distributed by age.

\begin{tabular}{|c|c|c|c|c|c|c|c|c|c|}
\hline \multirow{3}{*}{$\begin{array}{l}\text { Age group, } \\
\text { years }\end{array}$} & \multirow{3}{*}{ No. (\%) } & \multicolumn{5}{|c|}{ Cytology } & \multirow{3}{*}{$\begin{array}{c}\text { Uterine tumor } \\
\text { and abnormalities }\end{array}$} & \multirow{3}{*}{$\begin{array}{l}\text { Ovarian } \\
\text { tumor }^{2}\end{array}$} & \multirow{3}{*}{ Others ${ }^{3)}$} \\
\hline & & \multicolumn{4}{|c|}{ Cervix } & \multirow{2}{*}{$\begin{array}{c}\text { Endometrium } \\
\text { Hyperplasia/cancer }\end{array}$} & & & \\
\hline & & LSIL & HSIL & ASC-US & SCC & & & & \\
\hline $20-24$ & $26(0.9)$ & $1(3.8)$ & 0 & 0 & 0 & 0 & 0 & 0 & 0 \\
\hline $25-29$ & $94(3.3)$ & $1(1.1)$ & 0 & 0 & 0 & 0 & 0 & $1(1.1)$ & 0 \\
\hline $30-34$ & 282 (9.9) & $5(1.8)$ & 0 & $1(0.3)$ & 0 & 0 & 0 & $1(0.3)$ & 0 \\
\hline $35-39$ & $400(14.0)$ & $5(1.8)$ & $1(0.3)$ & 0 & 0 & 0 & 0 & $1(0.3)$ & 0 \\
\hline $40-44$ & $398(14.0)$ & $4(1.3)$ & $1(0.3)$ & 0 & 0 & 0 & $1(0.3)$ & $1(0.3)$ & $2(0.5)$ \\
\hline $45-49$ & 259 (9.1) & $3(1.0)$ & $1(0.4)$ & $1(0.4)$ & 0 & 0 & $6(2.3)$ & $1(0.4)$ & $1(0.4)$ \\
\hline $50-54$ & 257 (9.1) & $3(1.1)$ & 0 & 0 & 0 & 0 & $3(1.1)$ & 0 & $1(0.4)$ \\
\hline $55-59$ & 299 (10.5) & $1(1.3)$ & 0 & 0 & 0 & 0 & $1(0.3)$ & 0 & 0 \\
\hline $60-64$ & $287(10.1)$ & $1(0.3)$ & 0 & 0 & 0 & 0 & $1(0.3)$ & 0 & 0 \\
\hline $65-69$ & 281 (9.9) & $1(0.3)$ & 0 & 0 & 0 & 0 & $1(0.3)$ & $1(0.6)$ & 0 \\
\hline $70-74$ & $172(6.0)$ & $2(1.2)$ & 0 & 0 & 0 & 0 & 0 & $1(0.6)$ & $1(0.6)$ \\
\hline $75-79$ & $76(2.7)$ & $1(1.3)$ & 0 & 0 & 0 & 0 & 0 & 0 & 0 \\
\hline$<80$ & $19(0.7)$ & 0 & 0 & 0 & 0 & 0 & 0 & 0 & 0 \\
\hline \multirow{2}{*}{ Total } & \multirow{2}{*}{$2850(100)$} & $28(1.0)$ & $3(0.1)$ & $2(<0.1)$ & 0 & 0 & $13(0.5)$ & $7(0.2)$ & $5(0.2)$ \\
\hline & & & & & & $56(2.0)$ & & & \\
\hline
\end{tabular}

1) adenomyosis and uterine myoma (measuring 5 to $9 \mathrm{~cm}$ ). ${ }^{2)}$ unilobular cyst (measuring 3 to $5 \mathrm{~cm}$ ) suggestive for benign mass. ${ }^{3)}$ including vaginosis, cervical polyp, prolaps uteri.

of all subjects distributed by age class. Of the cervical smears, 33 (1.1\%) were classified as abnormal. Lowgrade cervical abnormalities were seen in 31 cases: 28 cases were classified as low-grade squamous intraepithelial lesion (LSIL) and 3 as high-grade squamous intraepithelial lesion (HSIL), 2 were atypical squamous cells of undetermined significance (ASC-US). No malignant case was detected within this study period. No case of cervical adenocarcinoma was found. None of the categories were clustered in any specific age group.

The most frequently detected gynecologic finding was uterine enlargement, with a peak reaching approximately $10 \%$ for age group 45 - 49 years. After 55 years, the frequency of uterine abnormalities decreased (Table 1). Ovarian tumor was detected in less than $1 \%$ of those aged 25 to 49 years, while those aged over 50 years showed less frequent. Table 1 summarized all other abnormal findings pointed out. No gynecologic abnormality was detected in $98 \%$ of cases.

\section{DISCUSSION}

The cervical smear is a widely used routine test with many benefits, especially in detecting early cervical changes that can be treated to limit dysplastic processes developing into cancer. The previous literatures found squamous intraepiterial lesion (SIL) in 3\% - 8\% of women aged 20 - 29 years and $1 \%$ - 5\% of over 30 -year age group [1-6]. Of the cervical smear tests on 7585 subjects in our study, $98.2 \%$ were negative. The incidence of abnormal cytologic findings (dysplastic changes and cervical cancer) in our study (1.2\%) was extremely low compared with other studies performed in developed countries [1-6].

Substantial data point to persistent human papillomavirus (HPV) infection as cervical cancer cause. The mean time between HPV infection and invasive cancer is about 15 years, and within 2 to 4 years of detection 15.5 to $25.5 \%$ of low-grade epithelial lesions become highgrade lesions [13-15]. The most frequently sexually transmitted disease (STD) worldwide is HPV infection $[16,17]$. Societies where sexual activity starts at a young age and where multiple partners are common are at high risk of exposure to HPV than in conservative societies. For example, a study in Jordan, one of the most conservative and religious countries, found that of the smears from 1176 women aged 18 - 70 years, 9 cases $(0.8 \%)$ were classified as ASC-US and 2 cases (0.2\%) were LSIL. Based on our result of city-agreed check-up, as- 
ymptomatic participants undergo a medical examination at public expense. The cultural tradition and high concern on check-up of our subjects restrict the likelihood of multiple sexual partners. This may explain why very low incidence of dysplastic changes and cervical cancer were found in our study group of women.

Of pelvic mass, uterine myomas and/or adenomyosis are estimated to be present in $20 \%-25 \%$ or reproductive-age women, indicating that they are one of the most common human neoplasma [18-20]. A myoma does not necessarily produce symptoms, and even very large ones may go undetected by the patient, particularly if she is obese. Symptoms from myomas depend on their location, size and state of presentation; symptoms are present in $35 \%-50 \%$ of patients with myomas. Ovarian tumors, cystic or solid, are also frequently asymptomatic and undetected by themselves. The diagnosis of these tumors is not usually difficult using ultrasonography at physical check-up. We observed lower frequency of uterine enlargement and ovarian tumors in our subjects.

The present study based on symptom-free population suggested annual gynecologic screening and proper follow-up programs even against asymptomatic women may remarkably reduce the probability of (pre) maliganant disease. Since the study sample was shown to be representative population of high-attitude toward screening but non-high income, most of our observations may have important implications in terms of public health.

\section{REFERENCES}

[1] Anttila, A., Ronco, G., Clifford, G., Bray, F., Hakama, M., Arbyn, M. and Weiderpass, E. (2004) Cervical cancer screening programmes and policies in 18 European countries. British Journal of Cancer, 91, 935-941.

[2] Bray, F., Loos, A., McCarron, P., Weiderpass, E., Arbyn, M., Møller, H., Hakama, M. and Parkin, D. (2005) Trends in cervical squamous cell carcinoma incidence in 13 European countries: Changing risk and the effects of screening. Cancer Epidemiology, Biomarkers \& Prevention, 14, 677-686. doi:10.1158/1055-9965.EPI-04-0569

[3] Greenlee, R., Hill-Harmon, M., Murray, T. and Thun, M. (2001) Cancer statistics, 2001. CA: A Cancer Journal for Clinicians, 51, 15-36. doi:10.3322/canjclin.51.1.15

[4] Hakama, M., Coleman, M., Alexe, D. and Auvinen, A. (2008) Cancer screening: Evidence and practice in Europe 2008. European Journal of Cancer, 44, 1404-1413. doi:10.1016/j.ejca.2008.02.013

[5] Johannesson, G., Geirsson, G., Day, N. and Tulinius, H. (1982) Screening for cancer of the uterine cervix in Iceland 1965-1978. Acta Obstetricia et Gynecologica Scandinavica, 61, 199-203. doi:10.3109/00016348209156556

[6] Mount, S. and Papillo, J. (1999) A study of 10,296 pediatric and adolescent Papanicolaou smear diagnoses in northern New England. Pediatrics, 103, 539-545. doi:10.1542/peds.103.3.539
[7] Nieminen, P., Kallio, M., Anttila, A. and Hakama, M. (1999) Organised vs. spontaneous Pap-smear screening for cervical cancer: A case-control study. International Journal of Cancer, 83, 55-58. doi:10.1002/(SICI)1097-0215(19990924)83:1<55::AID-I JC11>3.0.CO;2-U

[8] Dietrich, A., Tobin, J., Cassells, A., Robinson, C., Greene, M., Sox, C., Beach, M., DuHamel, K. and Younge, R. (2006) Telephone care management to improve cancer screening among low-income women: A randomized, controlled trial. Annals of Internal Medicine, 144, 563571.

[9] Lawson, H., Henson, R., Bobo, J. and Kaeser, M. (2000) Implementing recommendations for the early detection of breast and cervical cancer among low-income women. MMWR-Recommendations and Reports, 49, 37-55.

[10] Ng, E., Wilkins, R., Fung, M. and Berthelot, J. (2004) Cervical cancer mortality by neighbourhood income in urban Canada from 1971 to 1996. Canadian Medical Association Journal, 170, 1545-1549. doi:10.1503/cmaj.1031528

[11] Schoenberg, N., Hopenhayn, C., Christian, A., Knight, E. and Rubio, A. (2005) An in-depth and updated perspective on determinants of cervical cancer screening among central Appalachian women. Women Health, 42, 89-105. doi:10.1300/J013v42n02_06

[12] Yabroff, K., Lawrence, W., King, J., Mangan, P., Washington, K., Yi, B., Kerner, J. and Mandelblatt, J. (2005) Geographic disparities in cervical cancer mortality: What are the roles of risk factor prevalence, screening, and use of recommended treatment? The Journal of Rural Health, 21, 149-157. doi:10.1111/j.1748-0361.2005.tb00075.x

[13] Muñoz, N., Bosch, F., de Sanjosé, S., Herrero, R., Castellsagué, X., Shah, K., Snijders, P. and Meijer, C. (2003) Epidemiologic classification of human papillomavirus types associated with cervical cancer. The New England Journal of Medicine, 348, 518-527. doi:10.1056/NEJMoa021641

[14] Rocha-Zavaleta, L., Yescas, G., Cruz. R. and Cruz-Talonia, F. (2004) Human papillomavirus infection and cervical ectopy. International Journal of Gynecology \& $\mathrm{Ob}$ stetrics, 85, 259-266. doi:10.1016/j.ijgo.2003.10.002

[15] Tachezy, R., Saláková, M., Hamsíková, E., Kanka, J., Havránková, A. and Vonka, V. (2003) Prospective study on cervical neoplasia: Presence of HPV DNA in cytological smears precedes the development of cervical neoplastic lesions. Sexually Transmitted Infections, 79, 191196. doi:10.1136/sti.79.3.191

[16] Baseman, J. and Koutsky, L. (2005) The epidemiology of human papillomavirus infections. Journal of Clinical Virology, 32, S16-24. doi:10.1016/j.jcv.2004.12.008

[17] Clavel, C., Masure, M., Bory, J., Putaud, I., Mangeonjean, C., Lorenzato, M., Nazeyrollas, P., Gabriel, R. and Quereux, C., Birembaut, P. (2001) Human papillomavirus testing in primary screening for the detection of highgrade cervical lesions: A study of 7932 women. British Journal of Cancer, 84, 1616-1623. doi:10.1054/bjoc.2001.1845

[18] Levy, B. (2008) Modern management of uterine fibroids. Acta Obstetricia et Gynecologica Scandinavica, 87, 812 823. doi:10.1080/00016340802146912

[19] Parker, W. (2007) Uterine myomas: Management. Fertil- 
ity and Sterility, 88, 255-271.

doi:10.1016/j.fertnstert.2007.06.044

[20] Sankaran, S. and Manyonda, I. (2008) Medical manage- ment of fibroids. Best Practice \& Research Clinical Obstetrics \& Gynecology, 22, 655-667.

doi:10.1016/j.bpobgyn.2008.03.001 